\title{
Problemas éticos en las revistas biomédicas: las responsabilidades de sus directores
}

\author{
Herbert Stegemann* \\ * Médico psiquiatra do Hospital Vargas de Caracas. \\ Presidente, Asocianción de Editores de Revistas Biomédicas Venezolanas
}

Es una lógica aspiración de la mayoría de los directores y editores de las revistas biomédicas latinoamericanas ingresar al mundo de la respetabilidad científica. Con el correr del tiempo se ha hecho un enorme esfuerzo, particularmente en el curso de los últimos años. Gradualmente se incrementan las reuniones nacionales, regionales y continentales que se tienen en la materia. $\mathrm{Si}$ tomamos como referencia los principales índices y bases de datos electrónicas podemos apreciar el progresivo aumento en los registros. Sin embargo, el progreso es más lento de lo que deseamos. De tanto en tanto se lee y escucha que la producción científica que se origina en nuestro continente es de dudosa calidad y poco fiable. Se la menciona y referencia poco pero por otro lado se reconoce que en diversas áreas particularmente las biomédicas cubrimos temas que no son localizables o ni siquiera estudiadas en los países del llamado mundo desarrollado. En otras palabras: tenemos algo que ofrecer a la comunidad internacional. Un punto débil de las revistas en la región radica en su financiamiento irregular que afecta en primer lugar la periodicidad y puntualidad de aparición. El problema de la ética en investigación y publicaciones científicas es tomado muy en serio internacionalmente hasta el punto de que se están creando autoridades gubernamentales y académicas que recogen, estudian, evalúan e incluso sancionan a los infractores. Las sanciones son particularmente severas y logran la condena social y académica prácticamente de por vida a los infractores. Tomemos en cuenta que de una publicación puede depender la existencia o no de un medicamento en el mercado con sus consiguientes perfiles terapéuticos y de efectos secundarios reales o distorsionados. No olvidemos las gigantescas inversiones internacionales que requiere el desarrollo y comercialización de ese producto. Otro ejemplo podría ser la descripción de una supuesta nueva técnica quirúrgica para el abordaje de una patología específica con la cual se crearían falsas expectativas en torno a sus bondades o escasos riesgos. Un punto adicional gira en torno a la protección presente y futura de la persona que hace la denuncia de alguna irregularidad. Con frecuencia se trata de un profesional que apenas inicia su carrera mientras que el denunciado tiene un alto perfil profesional y social con el consiguiente poder e influencia: es un "opinion moulder" o forjador de opinión como se les conoce en el ambiente. El joven denunciante arriesga seriamente su desarrollo profesional si no cuenta con el debido amparo. El recurso más usual y aceptado para la divulgación del conocimiento científico es la revista o publicación periódica. Entramos así en la enorme responsabilidad que tienen los directores o editores de estos medios y en nuestro caso específico las revistas biomédicas, sean impresas en papel o electrónicas. La mayoría de los documentos producidos internacionalmente en torno a la ética en las publicaciones se centran en los autores de los artículos y apenas si mencionan de soslayo a los directores e integrantes de los cuerpos editoriales. Hemos hecho seguimiento de algunos casos específicos y logrado detectar situaciones que se hubieran podido evitar si las autoridades de la revista o de la institución que la respalda hubiesen tomado ciertas previsiones.

\section{Arquitectura}

1. ISSN e identificación del Depósito Legal. Francas inconsistencias que inmediatamente se detectarían en los índices y bases de datos internacionales. Una posible causa radica en que se "arrastra" el error de una edición a la siguiente sin verificar el documento de respaldo original.

2. Ausencia de un encabezado contentivo de la descripción del perfil editorial de la revista que permita a los interesados identificar rápidamente las características del contenido, la periodicidad, puntualidad, costo y distribución de la publicación.

3. Excesivo lujo tipográfico que encarece innecesariamente las ediciones y crea distorsión en la apreciación de la calidad científica del contenido.

4. Vigilar que al menos las tablas de contenido y los resúmenes de los artículos estén redactados en un segundo idioma, preferentemente inglés, el cual a su vez debe ser impecable desde el punto de vista de sintaxis y gramática.

5. Incorporación de una sección de Cartas al Editor con su respectiva normativa. Permite entre otros el reporte de casos aislados, informes preliminares o discusión razonada de temas actuales.

6. Incrementar el uso del recurso de los "suplementos" que permite la edición de números con contenidos especiales y que pueden ser financiados abiertamente por los interesados, generalmente la industria farmacéutica. Deberían en todo caso seguir los criterios de arbitraje.

7. Considerar seriamente la creación del formato electrónico.

\section{Normas}

1. Ausencia de normativas en torno al perfil profesional del Director y los integrantes del equipo editorial. Definir los criterios de nombramiento y remoción.

2. Normas de arbitraje inexistentes o en caso de existir 
no se aplican con uniformidad en todos y cada uno de los artículos

3. Normas para los autores cuyo contenido no se cumple, son incoherentes. Semejan un "collage" basado en otros documentos y con referencias inexistentes o no actualizadas. Un ejemplo característico de irregularidades es el relacionado con las citas y referencias bibliográficas.

4. Desconocimiento de las tendencias y normativas editoriales biomédicas internacionales. Debe mantenerse permanente contacto con organizaciones como el Council of Science Editors, la World Association of Medical Editors y el Comité Internacional de Editores de Revistas Médicas (Grupo Vancouver).

5. Extremar la vigilancia en los conceptos de autor y la originalidad del contenido de los artículos. Vigilar y reportar si el contenido fue presentado previamente en alguna reunión científica y hacer la debida referencia. Comprometer a los autores con documentos tales como la "Carta acompañante" (Covering letter).

6. Insistir que los autores hagan revisión de la literatura nacional y regional. Esto dinamizaría enormemente todo el sistema y es quizás uno de los mejores mecanismos que disponemos para darnos a conocer internacionalmente.

7. Tomar en consideración situaciones de posibles conflictos de interés y estar preparados para una clara y transparente discusión del punto. Definir por escrito la relación con las autoridades de la institución que respalda a la revista.

8. Lograr plena independencia de funcionamiento tomando como norte la imagen de seriedad científica de la publicación.

\section{Administrativas}

1. Duplicación de publicación del mismo artículo en ediciones separadas de la misma revista. Sugiere fallas de orden administrativo.

2. Indizaciones reportadas que en realidad dejaron de serlo, son inexistentes o lo opuesto: indizaciones existentes y que no aparecen señaladas en el perfil o encabezado de la revista.

3. Pautas publicitarias con ausencia de control en el contenido del texto e ilustraciones y ubicación inadecuada de los mismos en la paginación. A este punto se le puede sumar el desconocimiento casi total que existe en torno a la ética en la publicidad de productos y servicios situación que con frecuencia es aprovechada por el anunciante.

4. Irregularidades en la distribución y visibilidad de la publicación. El Director es responsable de poder garantizar que su revista llegue y quede registrada en al menos las principales bibliotecas, índices, bases de datos e instituciones además de su lista de suscriptores.

5. Si utiliza el sistema de "canje" con otras instituciones revisar periódicamente el cumplimiento de sus objetivos y sanear en consecuencia la lista.

\section{Equipo gerencial}

1. Contribuir en la formación de los equipos de relevo editorial preferentemente con integrantes profesionales jóvenes y con mística.

2. Creación y participación en cursos de formación de autores de artículos científicos, árbitros y gerencia de publicaciones científicas.

3. Formación de equipos de asesores en redacción científica, correctores de idioma, estadística, traducciones, fotografía e ilustraciones científicas.

\section{Integración}

1. Integración a organizaciones de editores científicos tanto nacionales como internacionales que permitan compartir experiencias

2. Desarrollar un programa para incorporación creciente en los índices y bases de datos nacionales e internacionales.

La tarea del Director y los integrantes del Cuerpo Editorial de una revista biomédica es ardua, meticulosa y muy exigente. En nuestro medio usualmente es una actividad no remunerada. Es importante evitar la monotonía y a tal fin conviene establecer un flujograma y programas de acción tomando en cuenta los objetivos a alcanzar. Estos a su vez deben actualizarse periódicamente y al alcanzarlos se obtendrá la gratificación de la misión cumplida.

\section{Correspondência:}

Herbert Stegemann

Apartado Postal 75.828

Caracas 1070-A Venezuela

hstegema@,cantv.net

\section{Como citar este artigo:}

Stegemann H. Problemas éticos en las revistas biomédicas: las responsabilidades de sus directores. Acta Cir Bras. [periódico na Internet] 2006 Jan-Fev;21(1). Disponível em URL: http:/www.scielo.br/acb 